\section{Commentary: Agroforestry leads to shifts within the gammaproteobacterial microbiome of banana plants cultivated in Central America}

\author{
Anna Maria Pirttilä * \\ Genetics and Physiology, University of Oulu, Oulu, Finland
}

Keywords: core microbiome, clonal propagation, green manure, endophyte, plant health

\section{A commentary on}

Agroforestry leads to shifts within the gammaproteobacterial microbiome of banana plants cultivated in Central America

by Köberl, M., Dita, M., Martinuz, A., Staver, C., and Berg, G. (2015). Front. Microbiol. 6:91. doi: 10.3389/fmicb.2015.00091

The microbiomes of organisms are fast becoming thoroughly studied by the development of next-generation sequencing techniques. As hundreds of strains can be identified within hours, the research on microbial community structures and their shifts under varying conditions is a current trend. And rightly so, as microbiomes are recognized as a key factor behind the health of an organism - whether be it human, or plant.

Köberl et al. (2015) studied the gammaproteobacterial microbiome of banana in response to geographical and agricultural factors, and discovered high numbers of Pseudomonadales, Enterobacteriales, Xanthomonadales, and Legionellales, and an exceptionally high richness of gammaproteobacteria as endophytes in banana. Endophytes, microbes living inside plant tissue without eliciting symptoms (Petrini, 1986), are shown increasingly important for the adaptation and fitness of the host. Members of this microbiome subgroup can protect the host from environmental stresses, induce plant resistance, and promote plant growth (Rosenblueth and Martinez-Romero, 2006; Hardoim et al., 2015). Köberl et al. found the banana gammaproteobacterial microbiome highly stable especially in the endophytic niche. Using profileclustering network analyses, they however saw differences in the communities between treatments. The greatest differences were observed in the rhizospheric communities between the geographical sites, Nicaragua and Costa Rica. Moderate, but important changes were observed within the epiphytic and endophytic microbiomes between the agroforestry systems, i.e., banana grown with and without green manure, which is used for nitrogen fertilization by legumes growing next to the crop plant. Specifically interesting were the stability of banana microbiome and the changes caused by the neighboring plants in each agroforestry system, which I discuss here.

Our most popular natural treat, banana (Musa spp.), is a clonally propagated plant, similar to many important food crops (McKey et al., 2010). Clonal propagation produces plant individuals identical by their genetic heritage and, for example, cultivated banana has almost completely lost the capacity for production of viable seeds. Therefore, banana plants are produced by clonal propagation from suckers, or through micropropagation (Singh et al., 2011). This is especially important when considering endophytic microbiomes of banana, for two reasons. 
First, whereas plant seeds can carry members of the microbiome to the next generation, only very few are transmitted through micropropagation (Koskimäki et al., 2010; Quambusch et al., 2014). The meristems that are used for micropropagation often host lower numbers of endophytes than other tissues (Pohjanen et al., 2013), and the diversity is lost by each subculture (Koskimäki et al., 2010). Therefore, an important factor to be considered when studying plant microbiome is the method of propagation, and the fact that the plant loses the majority of microbial members, or at least the diversity of the microbiome becomes very low, during micropropagation (Koskimäki et al., 2010; Quambusch et al., 2014).

Second, the plant microbiome has been shown to depend on the plant genotype (Berg and Smalla, 2009; Lundberg et al., 2012; Turner et al., 2013). Specifically, endophytic microbiomes are similar within species, cultivars, and their ancestors. For example, the endophytic microbiome correlates with host phylogeny, and the bacterial phylotypes are conserved regardless of geographic origin in maize (Zea mays L.) (Johnston-Monje and Raizada, 2011). Similar results have been obtained on rice (Oryza sativa L.) (Hardoim et al., 2011). Whereas maize and rice are seed-propagated, the genotype-dependency is obvious for clonally-propagated banana (Köberl et al., 2015). Such constant community of microbes is called a core microbiome, being stable through all phases of plant growth (Lundberg et al., 2012).

These two facts considered, Köberl et al. show that the core microbiome is not necessarily carried by seeds, but a plant acquires it from the environment as defined by its genome. This has not been thoroughly assessed in clonally propagated plants before. Our understanding of how the genome-genome based recognition occurs is still in its infancy. It is known that when the plant cell has been intruded, extracellular pattern-recognition receptors (PRRs) in the plasma membrane recognize microbe-associated molecular patterns (MAMPs) (Newman et al., 2013). Signals forwarded by the PRRs activate signaling cascades and initiate MAMP-triggered immunity, the basal plant defense response, defining the further plant defense reactions (Ausubel, 2005). These reactions modify the community structure of the plant microbiome, affecting both existing and entering microbial species (Podolich et al., 2015).

A microbe infecting the plant can shape the microbiome beyond the addition of one species. For example, phytopathogens create shifts in the structures of endophytic microbial communities (Reiter et al., 2002; Lian et al., 2008). The shifts caused by pathogens can have even more pronounced effects on the plant microbiome than genotype (Podolich et al., 2015). Milder, but observable changes in the plant endophyte communities can be detected after inoculation with beneficial microbes (Ardanov et al., 2012, 2016). The study by Köberl et al. reports changes in the gammaproteobacterial microbiome of banana due to neighboring vegetation (green manure). Banana plants growing next to Erythrina poeppigiana (Walp.) O. F. Cook, hosted lower numbers of Erwinia spp. in the leaves, and the bananas accompanied by Inga trees had higher numbers of endophytic bacteria belonging to genera Pseudomonas and Stenotrophomonas in their pseudostem and root tissues

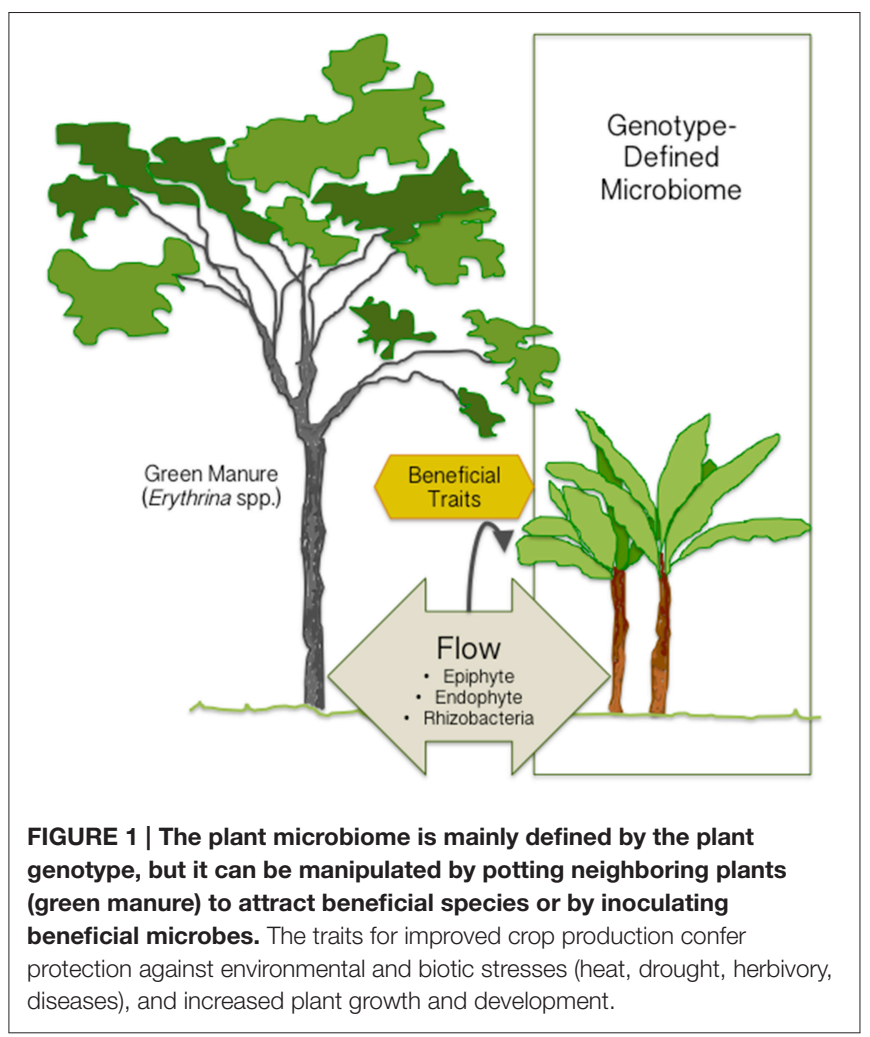

than plants without green manure. This could be the result of infection of banana plants by the microbes originating from the neighboring plants, which definitely deserves our attention.

The green manures have, so far, been considered beneficial in agriculture only due to fixed nitrogen provided by the legume-associated symbiosis. However, the study by Köberl et al. demonstrates the significance of neighboring plants in shaping plant microbiome (Figure 1) and thereby, possibly, affecting plant health. Even if the plant microbiome is mainly defined by genotype, we can manipulate it by potting neighboring plants to attract beneficial species, or through microbial inoculants. For designed manipulation of plant microbiomes, a post-microbiome era awaits to be entered. The traits carried by beneficial species need to be characterized to better understand how each strain induces positive effects on the plant. The sophisticated design of manipulating plant microbiome will help us in creating the future agriculture with reduced use of pesticides and fertilizers.

\section{AUTHOR CONTRIBUTIONS}

The author confirms being the sole contributor of this work and approved it for publication.

\section{ACKNOWLEDGMENTS}

I would like to thank Drs. A. C. Frank and M. V. Tejesvi for critically reading the manuscript. 


\section{REFERENCES}

Ardanov, P., Lyashchenko, S., Karppinen, K., Häggman, H., Kozyrovska, N. O., and Pirttilä, A. M. (2016). Effects of Methylobacterium sp. on emergence, yield, and disease prevalence in three cultivars of potato (Solanum tuberosum L.) were associated with the shift in endophytic microbial community. Plant Soil. doi: 10.1007/s11104-015-2500-y. Available online at: http://link.springer.com/ article/10.1007\%2Fs11104-015-2500-y

Ardanov, P., Sessitsch, A., Häggman, H., Kozyrovska, N., and Pirttilä, A. M. (2012). Methylobacterium-induced endophyte community changes correspond with protection of plants against pathogen attack. PLoS ONE 7:e46802. doi: 10.1371/journal.pone.0046802

Ausubel, F. (2005). Are innate immune signalling pathways in plants and animals conserved? Nat. Immunol. 6, 973-979. doi: 10.1038/ni1253

Berg, G., and Smalla, K. (2009). Plant species and soil type cooperatively shape the structure and function of microbial communities in the rhizosphere. FEMS Microbiol. Ecol. 68, 1-13. doi: 10.1111/j.1574-6941.2009.00654.x

Hardoim, P. R., Andreote, F. D., Reinhold-Hurek, B., Sessitsch, A., van Overbeek, L. S., and van Elsas, J. D. (2011). Rice root-associated bacteria: insights into community structures across 10 cultivars. FEMS Microbiol. Ecol. 77, 154-164. doi: 10.1111/j.1574-6941.2011.01092.x

Hardoim, P., van Overbeek, L., Berg, G., Pirttilä, A. M., Compant, S., Campisano, A., et al. (2015). The hidden world within plants: ecological and evolutionary considerations for defining functioning of microbial endophytes. Microbiol. Mol. Biol. Rev. 79, 293-320. doi: 10.1128/MMBR.00050-14

Johnston-Monje, D., and Raizada, M. N. (2011). Conservation and diversity of seed associated endophytes in Zea across boundaries of evolution, ethnography and ecology. PLoS ONE 6:e20396. doi: 10.1371/journal.pone.0020396

Köberl, M., Dita, M., Martinuz, A., Staver, C., and Berg, G. (2015). Agroforestry leads to shifts within the gammaproteobacterial microbiome of banana plants cultivated in Central America. Front. Microbiol. 6:91. doi: 10.3389/fmicb.2015.00091

Koskimäki, J. J., Nylund, S., Suorsa, M., and Pirttilä, A. M. (2010). Mycobacterial endophytes are enriched during micropropagation of Pogonatherum paniceum. Env. Microbiol. Rep. 2, 619-624. doi: 10.1111/j.1758-2229.2010. 00197.x

Lian, J., Wang, Z., and Zhou, S. (2008). Response of endophytic bacterial communities in banana tissue culture plantlets to Fusarium wilt pathogen infection. J. Gen. Appl. Microbiol. 54, 83-92. doi: 10.2323/jgam.54.83

Lundberg, D. S., Lebeis, S. L., Paredes, S. H., Yourstone, S., Gehring, J., Malfatti, S., et al. (2012). Defining the core Arabidopsis thaliana root microbiome. Nature 487, 86-90. doi: 10.1038/nature11237
McKey, D., Elias M., Pujol, B., and Duputié, A. (2010). The evolutionary ecology of clonally propagated domesticated plants. New Phytol. 186, 318-332.

Newman, M.-A., Sundelin, T., Nielsen, J. T., and Erbs, G. (2013). MAMP (microbeassociated molecular pattern) triggered immunity in plants. Front. Plant Sci. 4:139. doi: 10.3389/fpls.2013.00139

Petrini, O. (1986). "Taxonomy of endophytic fungi of aerial plant tissues," in Microbiology of the Phyllosphere, eds N. J. Fokkema and J. van den Heuvel (Cambridge: Cambridge University Press), 175-187.

Podolich, O., Ardanov, P., Zaets, I., Pirttilä, A. M., and Kozyrovska, N. (2015). Reviving of the endophytic bacterial community as a putative mechanism of plant resistance. Plant Soil 388, 367-377. doi: 10.1007/s11104-01 4-2235-1

Pohjanen, J., Koskimäki, J. J., and Pirttilä, A. M. (2013). "Interactions of meristemassociated endophytic bacteria," in Advances in Endophytic Research, eds V. C. Verma and A. C. Gange (New Delhi: Springer), 103-113.

Quambusch, M., Pirttilä, A. M., Tejesvi, M. V., Winkelmann, T., and Bartsch, M. (2014). Endophytic bacteria in plant tissue culture: differences between easyand difficult-to-propagate Prunus avium genotypes. Tree Physiol. 34, 524-533. doi: 10.1093/treephys/tpu027

Reiter, B., Pfeifer, U., Schwab, H., and Sessitsch, A. (2002). Response of endophytic bacterial communities in potato plants to infection with Erwinia carotovora subsp. atroseptica. Appl. Environ. Microbiol. 68, 2261-2268. doi: 10.1128/aem.68.5.2261-2268.2002

Rosenblueth, M., and Martinez-Romero, E. (2006). Bacterial endophytes and their interactions with hosts. Mol. Plant Microbe Interact. 19, 827-837. doi: 10.1094/MPMI-19-0827

Singh, H. P., Uma, S., Selvarajan, R., and Karihaloo, J. L. (2011). Micropropagation for Production of Quality Banana Planting Material in Asia- Pacific. New Delhi: Asia-Pacific Consortium on Agricultural Biotechnology (APCoAB), 92.

Turner, T. R., James, E. K., and Poole, P. S. (2013). The plant microbiome. Genome Biol. 14, 209. doi: 10.1186/gb-2013-14-6-209

Conflict of Interest Statement: The author declares that the research was conducted in the absence of any commercial or financial relationships that could be construed as a potential conflict of interest.

Copyright $\odot 2016$ Pirttilä. This is an open-access article distributed under the terms of the Creative Commons Attribution License (CC BY). The use, distribution or reproduction in other forums is permitted, provided the original author(s) or licensor are credited and that the original publication in this journal is cited, in accordance with accepted academic practice. No use, distribution or reproduction is permitted which does not comply with these terms. 